\title{
The rationale for shared decision making in mental health care; a systematic review of academic discourse
}

Karen James; Kingston University and St George's University of London, Joint Faculty of Health, Social Care and Education; K.James@sgul.kingston.ac.uk

Alan Quirk; Royal College of Psychiatrists, College Centre for Quality Improvement; Alan.Quirk@rcpsych.ac.uk

\begin{abstract}
Purpose: To identify and describe, in a systematic way, the various academic discourses on the rationale for SDM in mental health care, and so provide a comprehensive account of the ways in which this emerging field is being conceptualised in the research literature.

Methodology: A systematic review of peer reviewed papers presenting a rationale for SDM in mental health. Relevant databases were searched from inception to July 2016. Data were analysed using a thematic analysis which aimed to identify and describe different discourses on the rationale for SDM in mental health care. Data were extracted into a standardised data extraction form which contained fields representing the developing thematic framework, study information and research methodology.
\end{abstract}

Findings: Initial research returned 1616 papers, of which 175 were eligible for inclusion in this review. We developed ten distinct but interrelated themes which capture the various academic discourses on the rationale for SDM and represent some compelling arguments for SDM from a range of different perspectives including ethical, clinical, 'user' focussed, economic and political. Dominant narratives in the literature linked SDM to the recovery moment and person-centered care, and adherence and engagement with mental health services.

Limitations: We are unable to make any conclusions about the strength of evidence for these rationales. Our review was restricted to peer reviewed publications, published in English.

Implications: Our findings could be a useful framework to support the selection of outcome measures for SDM evaluations.

Originality: There have been no systematic reviews published in this area previously. 


\section{Introduction}

Shared Decision Making (SDM) is a process though which a person accessing health services and the clinician supporting them reach an agreed decision about the direction of care (Charles, Gafni, \& Whelan, 1997). It is a collaborative process which places equal value on the practitioner's scientific and clinical knowledge, and the personal experiences, goals and preferences of the individual ('experiential knowledge'). It is thought to be well established within general health services and there has been a large body of research reporting some evidence for the benefits of SDM within these settings, including reduced decisional conflict, and, amongst people accessing services, increased knowledge, satisfaction with care, participation in decision making and improved clinical outcomes (Austin, Mohottige, Sudore, Smith, \& Hanson, 2015; Durand et al., 2014; Joosten et al., 2008). Some have argued that SDM is particularly valuable when supporting someone who is experiencing 'chronic' health problems because, in these cases, decisions about care are likely to be made, revisited and revised on many occasions over a long period of time (McMullen, 2012). SDM is also thought to address issues of paternalism and inequity of power within the therapeutic relationship, and so could support the implementation of recovery-focussed practice within mental health services (Deegan \& Drake, 2006). However, compared to other areas of physical health such as obstetrics, cardiovascular disorders and end of life care, SDM within mental health has received far less attention in the academic literature and is not a part of routine clinical practice (Blanc et al., 2014). It has been suggested that there are unique challenges around the implementation of SDM in mental health because decisions are often complex, there isn't a strong evidence base for mental health interventions, some people may be too unwell to participate in the decision making process, and elements of coercion are a common part of practice in acute settings (Seale, Chaplin, Lelliott, \& Quirk, 2006; Simmons, Hetrick, \& Jorm, 2010)

SDM is therefore an emerging area of interest in mental health care, which could form an important part of clinical practice, however the evidence for its impact on clinical and 'user' focussed outcomes and experiences of care is currently limited. The aim of our review is to identify and describe, in a systematic way, the various academic discourses on the rationale for SDM in mental health care. By doing this we provide a comprehensive account of the ways in which this emerging field is being conceptualised in the research literature; a prominent and influential source of knowledge and information. These discourses are important because they will shape how SDM is defined and how it is evaluated, and will also reveal ways of thinking and what is valued within the academic community (Hyland, 2004). 


\section{Method}

\section{Eligibility criteria}

Our study aimed to review academic discourses on the rationale for shared decision making in mental health care published in scientific journals. We defined a 'rationale for shared decision making' as any argument or reason for shared decision making in mental health care outlined in a journal paper. This did not include raw data or findings reported in the result sections of primary research papers.

Inclusion criteria were:

a) Includes at least one statement presenting a rationale for SDM in mental health care

b) Available in printed or downloadable form

c) Available in English

Exclusion criteria were:

a) Discusses the use of SDM in general health care only

b) Reports data in the results section that points to the benefits of SDM, but is not presented as a rationale for SDM by authors (i.e. in the discussion or conclusion).

\section{Search strategy and analysis}

The databases PubMed, Embase, CINHAL and PsycINFO were searched from inception to July 2016 using search terms (outlined in Appendix 1) identified from the title, abstract or keywords. Retrieved studies were exported into RefWorks and duplicates were removed. The search was completed by one reviewer (KJ), who screened titles and abstracts against the eligibility criteria (Figure 1) Data were analysed using a thematic analysis which aimed to identify and describe different discourses on the rationale for shared decision making in mental health care. Data were extracted into a standardised data extraction form which contained fields representing the developing thematic framework, study information (authors, country, etc.) and research methodology. One reviewer (KJ) extracted the data and assessed eligibility of all relevant papers. A subsample of the extracted data (15 papers) were examined by a second reviewer $(\mathrm{AQ})$ to determine the reliability of the final framework; there was $100 \%$ concordance between reviewers. Initial themes were developed through a preliminary analysis of eight key papers identified by the editors of this special edition and represented the different different discourses on the rationale for shared decision making in mental health care present in the literature. These themes were reviewed and discussed at a meeting between authors $\mathrm{KJ}$ and $\mathrm{AQ}$ and the editors, and it was agreed that they were a reliable and valid representation of these data. The themes were subsequently refined 
through an iterative process during data extraction at regular meetings between the authors as new data emerged.

\section{Results}

A flow diagram outlining the study retrieval process is displayed in Figure 1. The 175 papers included in our analysis comprised qualitative interview and focus group studies $(n=42)$, quantitative cross sectional surveys $(n=27)$, quantitative analysis of transcripts from clinical consultations $(n=5)$, evaluations of interventions $(n=20)$, mixed methods research $(n=5)$, narrative $(n=43)$ and systematic $(n=13)$ reviews, commentary or editorial pieces $(n=6)$, and studies using 'other' methods such as routine data analysis and case study research $(n=5)$.

Figure 1: Flow diagram of study retrieval, adapted from adapted from the Preferred Reporting Items for Systematic Review and Metaanalyses (PRISMA) flow diagram (Moher et al., 2009)

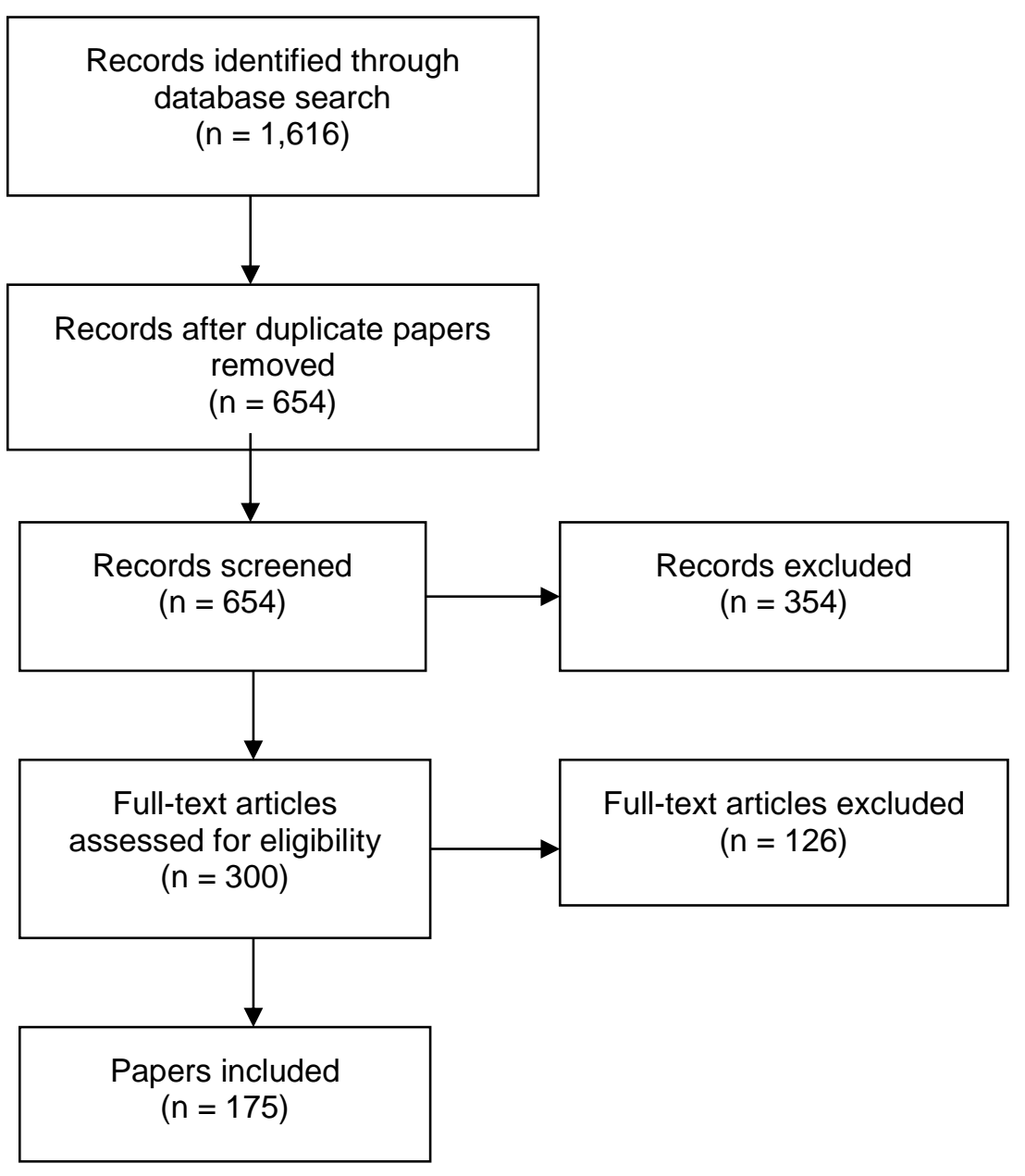

Just under half of all studies were conducted in the USA, followed by Germany and the UK (Table 1). 
Table 1. Number of publications by country

\begin{tabular}{lll}
\hline Country & $\boldsymbol{n}$ & $\%$ \\
\hline USA & 85 & 49 \\
UK & 20 & 11 \\
Germany & 19 & 11 \\
Netherlands & 11 & 6 \\
Spain & 9 & 5 \\
Australia & 8 & 5 \\
Canada & 5 & 3 \\
Denmark & 4 & 2 \\
Switzerland & 2 & 1 \\
Japan & 2 & 1 \\
Sweden & 2 & 1 \\
Italy & 1 & 1 \\
Greece & 1 & 1 \\
Hong Kong & 1 & 1 \\
Korea & 1 & 1 \\
Norway & 1 & 1 \\
Saudi Arabia & 1 & 1 \\
Taiwan & 1 & 1 \\
Multi national & 1 & 1 \\
\hline
\end{tabular}

An analysis of publications over time revealed how arguments for the implementation of SDM in mental health care have become increasingly prevalent in the research literature. Our results, displayed in Figure 2, show over an eight-fold increase in the number of publications presenting rationales for SDM in mental health published in $2003(n=4)$ vs 2015 $(n=33)$. 
Figure 2: Publications presenting a rationale for SDM over time

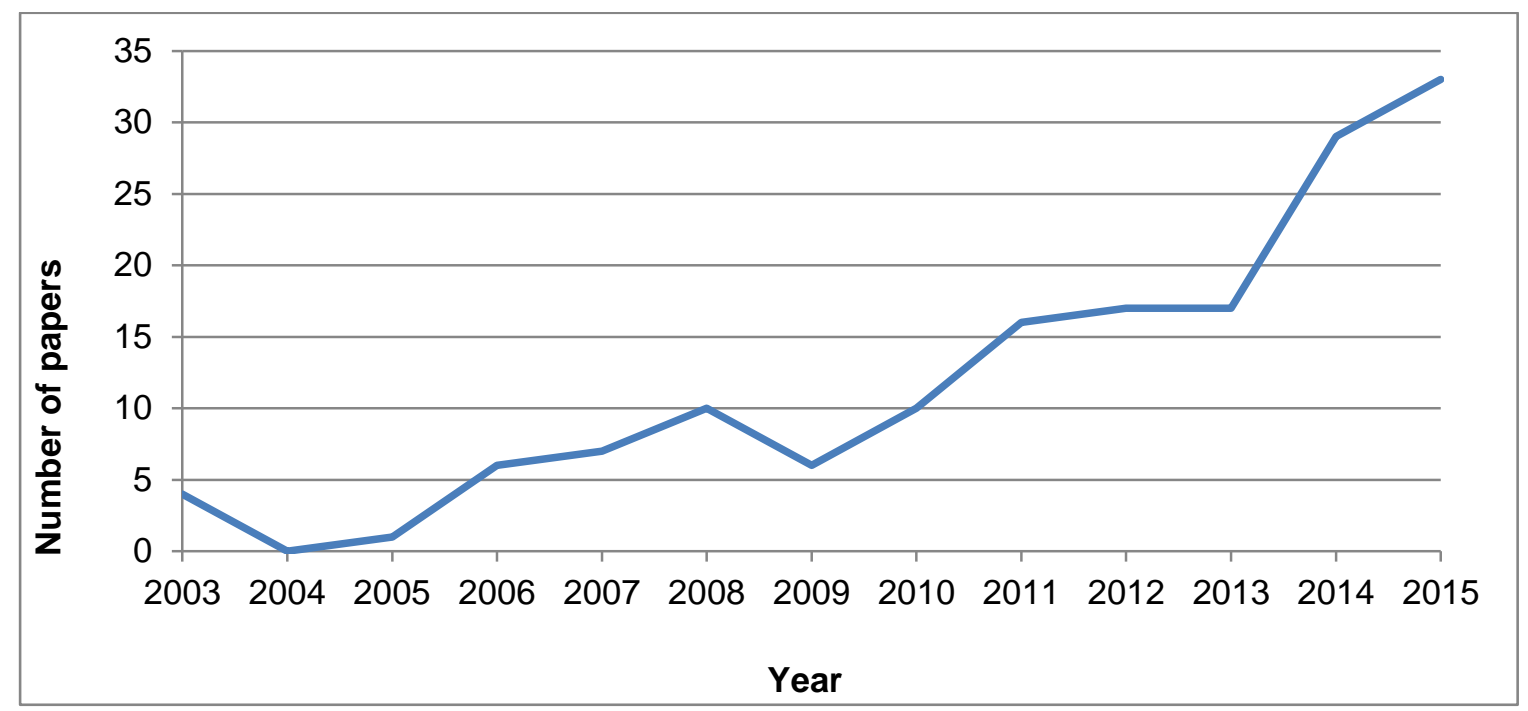

Through our analysis we developed ten distinct but interrelated themes which capture the various academic discourses on the rationale for SDM in mental health care. These are outlined in Table 2, along with their prevalence in the literature, and are described in more detail below.

Table 2. Prevalence of academic discourses on the rationale for SDM in mental health care

\begin{tabular}{llcc}
\hline Theme & $n$ & $\%$ \\
\hline 1 & $\begin{array}{l}\text { SDM is aligned with other approaches currently considered 'best practice' } \\
\text { in mental health care }\end{array}$ & 109 & $62 \%$ \\
2 & SDM fosters adherence and engagement with mental health services & 86 & $49 \%$ \\
$3 \quad \begin{array}{l}\text { People who access mental health services want to be involved in decisions } \\
\text { about their care }\end{array}$ & 65 & $37 \%$ \\
$4 \quad \begin{array}{l}\text { Services have a legal and ethical obligation to implement SDM } \\
5\end{array} \quad$ SDM is empowering & 47 & $27 \%$ \\
6 & $\begin{array}{l}\text { SDM draws on experiential knowledge leading to better decisions about } \\
\text { mental health care }\end{array}$ & 35 & $26 \%$ \\
\hline 7 & SDM strengthens the therapeutic relationship & 25 & $14 \%$ \\
8 & SDM protects against coercion present in the mental health system & 22 & $13 \%$ \\
9 & $\begin{array}{l}\text { People experiencing mental health challenges are able to be involved in } \\
\text { decisions about their care }\end{array}$ & 22 & $13 \%$ \\
10 & SDM is cost effective & 5 & $3 \%$
\end{tabular}




\section{SDM is aligned with other approaches currently considered 'best practice' in mental health care}

The most prevalent narrative within the academic literature positioned SDM as strongly aligned with the principles of person-centred care, user participation and personal recovery. It was seen to embody the 'processes' underpinning these paradigms and SDM tools a way of actualising these principles by allowing practitioners to put them into practice (Adams \& Drake, 2006; Drake, Deegan, \& Rapp, 2010). SDM was therefore viewed as being central to the 'modernisation' of mental health services, an important part of a larger movement concerned with the transformation of services from traditional 'paternalistic' approaches to care into those which prioritise the involvement and empowerment of people experiencing mental health challenges. Within these narratives some related this to an increased 'consumerism' within health services (McMullen, 2012; Woltmann \& Whitley, 2010). The term 'consumer' was frequently used in papers from the USA, which made up almost half of those included in this review (Table 1). In support of this argument, many academics cited policy documents, clinical guidance or reports from professional or third sector organisations which called for the implementation of shared decision making in mental health. SDM was also described, in five papers, as being 'an important component of evidence based medicine' (Adams \& Drake, 2006; Curtis et al., 2010; Drake, 2009; Perestelo-Perez, Gonzalez-Lorenzo, Perez-Ramos, Rivero-Santana, \& Serrano-Aguilar, 2011; Velligan, Roberts, Sierra, Fredrick, \& Roach, 2016) because shared decision making promotes the use of research knowledge, and because 'evidence-based medicine asserts that the inclusion of patient preferences, along with scientific evidence and clinician skills, should be a pillar of medical decision making' (Drake, 2009).

\section{SDM fosters adherence and engagement with mental health services}

This was another dominant narrative, largely centred around engagement with medication, which was supported by citations of research illustrating that SDM can improve concordance within both mental health and general health services (e.g. Bauer et al., 2014; Loh et al., 2007), the rationale being that if people are involved in decisions about their care, the chosen course of action is likely to be concordant with the values, preferences and needs of that individual, and so they are more likely to support the agreed course of action and follow it through. This was seen as the primary way in which SDM might improve clinical outcomes, and so is a compelling argument for its implementation, particularly given the high rates of disengagement, and discontinuation of medication with mental health services, often 
attributed to a lack of person centered practice, and the adverse effects of psychiatric medication (Kaminskiy, 2015). Whilst some papers called this 'engagement', 'follow through', or 'concordance' with care, SDM was most often described as increasing the 'likelihood of adherence to treatment' (e.g. Goldner et al., 2011; Loh et al., 2007). However some authors were critical of this language because they felt it was not synonymous with the values of SDM. For example, because the term 'adherence' implies a rule is being followed (Mahone, Maphis, \& Snow, 2016), reinforces the power of the clinician, or does not recognise a decision to stop taking medicine as a rational choice, informed by lived experience (Deegan, 2007). Others noted that 'adherence' is not the primary goal of most shared decision making interventions (Stein et al., 2013) and that non-adherence can indicate a breakdown of the decision making process so may be a positive outcome in cases where the care plan does not meet the goals of the individual (Hegedus \& Kozel, Dec 2014; Seale et al., 2006)

\section{People who access mental health services want to be involved in decisions about their care}

Evidence that the majority of people who access mental health services want to be involved in decisions with their care was frequently cited as a clear rationale for the implementation of SDM (e.g. De las Cuevas, Rivero-Santana, Perestelo-Perez, Perez-Ramos, \& SerranoAguilar, 2012; Hamann, Cohen, Leucht, Busch, \& Kissling, 2005; Mahone, 2008; Park et al., 2014; Patel \& Bakken, 2010), as was research showing that people, and those accessing mental health services in particular, often do not experience the level of participation they would like (e.g. Butler, 2014; Hamann et al., 2008; Hetrick, Simmons, \& Merry, 2008). Discourses on this theme often focussed on the 'multi-factorial and dynamic' nature of SDM preferences (Chong, Aslani, \& Chen, 2013), which are likely to change during different points in a person's recovery. Many authors argued this was particularly important to consider in mental health care because people are often supported by services over long periods of time, during which they are likely to experience many fluctuations in their mental health. Authors therefore underlined the importance of discussing people's preferences for SDM and ensuring that these conversations are ongoing over time (e.g. Clarke, 2015). There was some discussion not only of how preferences might vary over time, but also with different decisions, within different healthcare contexts, and between different groups. For example, a number of papers cited examples of how cultural factors, such as individualism vs collectivism, or perceptions of practitioners as figures of authority, can influence preferences for SDM (Clarke et al., 2015; Curtis et al., 2010; Patel, Bakken, \& Ruland, 2008; Patel \& Bakken, 2010). Within these discourses a number of authors discussed a conceptual differentiation between the process of decision making and the final act of making the decision itself (Chong et al., 2013; De las Cuevas et al., 2012; McMullen, 2012). For 
example, in one study $90 \%$ of participants wanted to be involved in decisions in their care, however $76 \%$ preferred to leave the final decision to the clinician (De las Cuevas et al., 2011). In other studies however, the person accessing the service was almost always described as having the final say (McMullen, 2012; Woltmann \& Whitley, 2010). Whist it has been noted that some disagreement exists in this area (Kaminskiy, 2015) the most dominant narrative amongst papers in in our review was that the focus of SDM should be on the process of decision making, rather than consensus on the final decision.

\section{Services have a legal and ethical obligation to implement SDM}

Around a quarter of papers framed shared decision making as an 'ethical imperative' (Deegan, 2010), citing key principles of biomedical ethics, such as self-determination over one's own body, and informed consent and choice, which were seen to be central to SDM. Authors also highlighted how these principles are now becoming legal standards for medical care (Birkeland \& Gildberg, 2016; Drake et al., 2010; Drake, Cimpean, \& Torrey, 2009; Joosten et al., 2008; Joosten, de Jong, de Weert-van Oene, Sensky, \& van der Staak, 2009). These arguments were not explored in-depth in these papers, however it was noted that there may be strong ethical arguments for a temporary shift to a paternalistic mode of decision making in cases where a person's insight is impaired (Seale et al., 2006). This is discussed further (theme 9) below.

\section{SDM is empowering}

Also present in a quarter of papers was the discourse of empowerment. Authors described empowerment as being at the heart of SDM practice because SDM processes enable people to voice their experiences and desires, and allow them to take control over their care and 'steer their own path of recovery' (Chan \& Mak, 2012). These key elements of SDM were also identified as being common themes within personal recovery narratives (Shepherd, Shorthouse, \& Gask, 2014) and were thought to foster improvements in selfesteem, self-confidence and self-efficacy. In this way, shared decision making was viewed as being therapeutic in itself (Morant, Kaminskiy, \& Ramon, 2015) and authors described how it can become an important part of the support offered by professionals, for example, by helping people who are depressed overcome feelings of helplessness (Raue et al., 2010). These narratives had links to those around following through with care (theme 2) because some believed the process of empowerment would lead to people feeling more able to take responsibility for their own care. It was hypothesised that this could be another mechanism through which SDM improves clinical outcomes (Edbrooke-Childs et al., 2016), and may also reduce self-stigma and stigmatising attitudes amongst professionals about the ability of 
people experiencing mental health challenges to participate in their care (Ahmed, McCaffery, \& Aslani, 2016; Butler, 2014; Hamann, Leucht, \& Kissling, 2003; Patel et al., 2008)

\section{SDM draws on experiential knowledge leading to better decisions about mental health care.}

This narrative described experiential knowledge as being equally as important as scientific and clinical knowledge in the decision making process. Within this discourse, decisions in mental health care were described as being particularly 'complex', 'preference sensitive' and involving more 'decisional uncertainty' compared to those within general medicine (e.g. Adams, 2006; Betinger, 2014; Morant, 2015). Authors argued that there are many support options available to people experiencing mental health challenges, which have similar efficacy, or a limited evidence base, yet divergent risks and side effects that could have a significant impact on their quality of life. For example, a person with a diagnosis of depression could choose from a range of different psychosocial interventions, such as Cognitive Behavioural Therapy, Mindfulness or Peer Support, or psychotropic medications, or some combination of them. These decisions were commonly presented as being 'not just medical but personal' (Deegan, 2010; Deegan 2014) because they involve complex risk/benefit trade-offs between clinical efficacy, life goals and side effects (Drake et al., 2010). Lived experience was therefore seen as equally important as clinical knowledge in the decision making process and essential for the development of care plans that are aligned with the values and needs of the individual.

\section{SDM protects against coercion present in the mental health system}

These narratives presented SDM as an 'emancipatory' practice (Deegan, 2007), which counteracts 'coercion' and 'power asymmetry' inherent within the mental health system. This notion of power was identified as a unique characteristic of mental health care, largely due to Mental Health Act legislation which was seen to create a specific 'legal context' not present within other health services (Beitinger, Kissling, \& Hamann, 2014; Kaminskiy, 2015; Morant et al., 2015). For example, because mental health treatment can be enforced against a person's will through the use of community treatment orders or compulsory detention in hospital. Even if this legislation was not actively enforced, authors described how an implicit threat, or fear, of coercion can be a barrier to open and honest discussions about an individual's mental health and can stop them from playing an active part in decisions about their care (Deegan, 2007; Morant et al., 2015). By recognising people accessing mental health services as experts alongside clinicians, promoting mutual respect, open and honest communication and a collaborative way of working, SDM was seen as a way for people to take back control (Hamann, Cohen, Leucht, Busch, \& Kissling, 2007; Lee King et al., 2015; 
Simos, 2012). Some also argued that the successful implementation of SDM could have a transformative impact on the 'professional identity' of psychiatry, distancing the profession from its historic reputation as an agent of social control and bringing it more in line with the rest of medicine by sharing ideals of good practice in relation to SDM (Quirk, Chaplin, Lelliott, \& Seale, 2012). It has, however, been questioned whether SDM is feasible during mental health crisis, or within acute settings, where people may be seen as too unwell to make informed decisions about their care, and where coercion or potential for coercion is part of everyday practice (Quirk et al., 2012; Seale et al., 2006; Stacey et al., 2016)

\section{SDM strengthens the therapeutic relationship}

This rationale featured in just a few papers, and on the whole, was not explored in any detail. This discourse involved descriptions of how SDM encompasses 'the cornerstones that form the basis of good therapeutic relationships' (Corrigan et al., 2012), such as empathy, genuineness, trust and mutual understanding. As described above, SDM was seen to break down power imbalances and promote communication and collaboration between people who are experiencing mental health challenges and the clinicians supporting them. This was identified as an under-researched area (Eliacin, Salyers, Kukla, \& Matthias, 2015), however authors cited a small number of studies that found SDM had a positive impact on the therapeutic relationship (Bieber et al., 2006; Matthias et al., 2014). Although there was some disagreement; for example one paper reported that psychiatrists felt people became 'more difficult' after they had received SDM training, and so suggested that SDM may introduce more conflict into these relationships (Hamann et al., 2011).

\section{People experiencing mental health challenges are able to be involved in decisions about their care}

This discourse acted to counter narratives which questioned whether some people experiencing mental health challenges have the capacity to be involved in decisions about their care. Much of this debate centred around people with a diagnosis of schizophrenia (Chan \& Mak, 2012) and this was presented as a unique challenge to SDM in mental health vs general health services because of the potential impact of the illness on an individual's cognitive functioning, capacity and insight (Kaminskiy, 2015; Seale et al., 2006). Some authors suggested that SDM may not be possible during a mental health crisis, for example, when a person is refusing anti-psychotic medication during an acute psychotic episode, or when someone who is actively suicidal wants to be discharged from hospital (Hamann \& Heres, 2014). This discourse challenged these arguments by citing evidence that 'decision incapacity is the exception rather than the rule, even among people with psychotic conditions' (Deegan, 2014). For example, that studies of informed consent (Roberts et al., 
2002), decisions around medication (Bunn, O'Connor, Tansey, Jones, \& Stinson, 1997) or treatment goals (Becker \& Drake, 2001), have concluded that people who experience psychosis are able to make rational choices. Authors argued that because it is clinicians themselves who make decisions about capacity there is a risk of an abuse of power, for example because a clinician may assume a lack of capacity in cases where an individual disagrees with them about their care (Deegan, 2014; Morant et al., 2015). Drawing comparisons with support for 'other patients' who may have limited education or learning difficulties, some argued that to ensure that all people accessing mental health services are able to participate, 'mental capacity development' should be incorporated into the SDM process (Drake et al., 2009; Gioia et al., 2014). Several authors also suggested that advance directives could be used in cases where a person's capacity is severely limited (Drake et al., 2010; Drake et al., 2009; Ramos Pozon, 2016).

\section{SDM is cost effective}

Five papers featured economic arguments for SDM, although one author noted that the evidence for the impact of SDM on mental health service costs is limited (Latimer, Bond, \& Drake, 2011). It was suggested that SDM may reduce costs by improving outcomes and so reducing use of mental health services, and that it may also decrease the costs associated with the use of psychotropic medications by reducing unnecessary, or unwanted prescriptions (Adams \& Drake, 2006; Ahmed et al., 2016; De las Cuevas \& Penate, 2014; Latimer et al., 2011; Mistler \& Drake, 2008).

\section{Discussion}

We identified ten distinct but interrelated themes which capture the various academic discourses on the rationale for SDM in mental health care. These discourses represent some compelling arguments for SDM from a range of different perspectives including ethical, clinical, 'user' focussed, economic and political, which are likely to speak to different audiences. For example, the cost-effectiveness discourse might resonate with policy makers and commissioners, while the adherence/engagement discourse may appeal most to clinicians. Whilst our findings do not indicate which rationales for SDM are the most robust (the focus of our review was content, not evidence), they do illustrate differences in the prevalence, or use, of these arguments within the literature, and so the potential strength of these discourses in terms of their value amongst researchers, and their influence within and outside of academia.

These discourses are situated within a specific socio-cultural and political context, and are largely comprised of accounts from 'Western' academics (Table 1), and so may not 
necessarily be representative of discussions around the rationales SDM within non-Western cultures. The most dominant narrative in the literature linked SDM to the recovery moment, person-centered care, and, in the US, an 'increased consumerisation' of health services (McMullen, 2012), which are all seen as being part of a 'fundamental shift' in perceptions of mental illness and the delivery of mental health services across the Western world (Ramon, Healy, \& Renouf, 2007). In line with these recent advances in mental healthcare delivery, we found a substantial increase in the numbers of papers presenting arguments for SDM over the last ten years (Figure 1). We expect that the SDM discourses outlined in this paper will evolve over time alongside developments in mental health research, policy and practice.

A dominant narrative, present in just under half of all papers, focussed on the positive impact of SDM on adherence and engagement with mental health services. This was criticised by some authors who argued that 'adherence' is a paternalistic concept, and does not reflect the values of SDM (Hegedus \& Kozel, Dec 2014; Mahone et al., 2016). As outlined above, it is likely that this rationale will appeal most to clinicians, whilst people who are accessing mental health services may place more value on arguments around empowerment or improved therapeutic relationships, which were less prevalent in the literature. It is perhaps unsurprising that adherence/engagement is a strong academic discourse as the audience, or readership, of these journals is likely to comprise many more clinicians than people accessing mental health services, and many academics are clinicians themselves. However, we know from previous research that people experiencing mental health challenges often place value on different outcomes than clinicians (Crawford et al., 2011; Kabir \& Wykes, 2010), and that these are frequently neglected by researchers (Faulkner, 2015). The academic literature is a prominent and influential source of knowledge, and so if much of the discussion and research evidence around SDM is in relation to adherence, then there is a risk that this becomes a defining feature, or focus of SDM itself. It is therefore important that academics place equal weight on 'user focussed' outcomes to ensure that new knowledge around SDM reflects the values and principles central to the approach, and the priorities of the people it ultimately aims to help.

We hope this paper will make readers more alive to which discourse or discourses they are operating in, especially when they are considering outcome measures. We have provided a comprehensive account of the arguments or hypotheses presented in the academic literature for the potential benefits of SDM, which could be a useful framework to support the selection of outcomes. For example, studies of the relationship between SDM and empowerment might include measures of self-esteem, self-efficacy or self-confidence, prominent in discourses of empowerment (theme 5), whilst those looking at the impact on the therapeutic relationship could examine empathy, trust or understanding (theme 8). Our 
findings could also help researchers think about the possible mechanisms of action for SDM, for example SDM may improve clinical outcomes by increasing engagement, or it might improve therapeutic relationships by protecting against coercion within mental health services.

These discourses present some compelling arguments for the implementation of SDM within mental health care, however more research is needed to illustrate if, and how, SDM shapes the experiences and outcomes of people experiencing mental health challenges. SDM is not a unitary phenomenon, and so more studies of naturally occurring decision-making in mental health settings are also needed, to help us better understand the skills participants use to make SDM feel like SDM, because without this, the benefits of SDM will be lost (Quirk et al., 2012). Academic discourses around SDM have been criticised as presenting an 'idealised' view, far removed from the challenges and realities of routine clinical practice (Angell \& Bolden, 2015). Mental health service users are likely to meet practitioners in both routine encounters (e.g. outpatient consultations) and crisis situations (e.g. assessments for compulsory admission to hospital), and in some psychiatric contexts the threat of compulsion is overt or barely concealed, making the ideal of SDM very difficult to achieve (Quirk, 2015). Indeed, there are instances where it can be argued that it is more ethical for the clinician to take a more directive approach in decision-making, if it were to prevent a mental health crisis leading to compulsory hospitalisation (ibid). There are likely to be many other barriers to SDM (discussed later in this edition, REF), however our findings suggest there might also be many benefits if they can be overcome.

Limitations

Ours was a review of content and not evidence so we are unable to make any conclusions about the strength of evidence for the rationales we have identified. Our review was restricted to peer reviewed publications and so different arguments for SDM may be presented in other sources of information, such as clinical text books, the grey literature or narratives from lived experience. The selection of papers was performed by one reviewer only. We only reviewed papers published in English, and, whilst there were few papers published in other languages, these may have offered a different perspective on SDM.

\section{References}

Adams, J. R., \& Drake, R. E. (2006). Shared decision-making and evidence-based practice. Community Mental Health Journal, 42(1), 87-105. doi:10.1007/s10597-005-9005-8 
Ahmed, R., McCaffery, K. J., Silove, N., Butow, P., Clarke, S., Kohn, M., \& Aslani, P. (2016). The evaluation of a question prompt list for attention-deficit/hyperactivity disorder in pediatric care: A pilot study. Research in Social \& Administrative Pharmacy : RSAP, doi:S1551-7411(16)00047-4

Ahmed, R., McCaffery, K. J., \& Aslani, P. (2016). Development and validation of a question prompt list for parents of children with attention-deficit/hyperactivity disorder: A delphi study. Health Expectations: An International Journal of Public Participation in Health Care and Health Policy, 19(2), 234-252. doi:10.1111/hex.12341

Angell, B., \& Bolden, G. B. (2015). Justifying medication decisions in mental health care: Psychiatrists' accounts for treatment recommendations. Social Science \& Medicine (1982), 138, 44-56. doi:10.1016/j.socscimed.2015.04.029

Austin, C. A., Mohottige, D., Sudore, R. L., Smith, A. K., \& Hanson, L. C. (2015). Tools to promote shared decision making in serious illness: A systematic review. JAMA Internal Medicine, 175(7), 1213-1221.

Bauer, A. M., Parker, M. M., Schillinger, D., Katon, W., Adler, N., Adams, A. S., . . Karter, A. J. (2014). Associations between antidepressant adherence and shared decisionmaking, patient-provider trust, and communication among adults with diabetes: Diabetes study of northern california (DISTANCE). Journal of General Internal Medicine, 29(8), 1139-1147. doi:http://dx.doi.org/10.1007/s11606-014-2845-6

Becker, D. R., \& Drake, R. E. (2001). Improving employment outcomes for people with severe psychiatric disabilities. Improving Mental Health Care: Commitment to Quality, , 235 À240.

Beitinger, R., Kissling, W., \& Hamann, J. (2014). Trends and perspectives of shared decision-making in schizophrenia and related disorders. Current Opinion in Psychiatry, 27(3), 222-229. doi:10.1097/YCO.0000000000000057

Bieber, C., Müller, K. G., Blumenstiel, K., Schneider, A., Richter, A., Wilke, S., . . Eich, W. (2006). Long-term effects of a shared decision-making intervention on physician-patient interaction and outcome in fibromyalgia: A qualitative and quantitative 1 year follow-up of a randomized controlled trial. Patient Education and Counseling, 63(3), 357-366. 
Birkeland, S., \& Gildberg, F. A. (2016). Mental health nursing, mechanical restraint measures and patients' legal rights. The Open Nursing Journal, 10, 8-14. doi:10.2174/1874434601610010008

Blanc, X., Collet, T., Auer, R., Fischer, R., Locatelli, I., Iriarte, P., . . Cornuz, J. (2014). Publication trends of shared decision making in 15 high impact medical journals: A fulltext review with bibliometric analysis. BMC Medical Informatics and Decision Making, 14(1), 1.

Bunn, M. H., O'Connor, A. M., Tansey, M. S., Jones, B. D. W., \& Stinson, L. E. (1997). Characteristics of clients with schizophrenia who express certainty or uncertainty about continuing treatment with depot neuroleptic medication. Archives of Psychiatric Nursing, 11(5), 238-248.

Butler, A. M. (2014). Shared decision-making, stigma, and child mental health functioning among families referred for primary care-located mental health services. Families, Systems \& Health : The Journal of Collaborative Family Healthcare, 32(1), 116-121. doi:10.1037/fsh0000004

Chan, K. K., \& Mak, W. W. (2012). Shared decision making in the recovery of people with schizophrenia: The role of metacognitive capacities in insight and pragmatic language use. Clinical Psychology Review, 32(6), 535-544. doi:10.1016/j.cpr.2012.06.001

Charles, C., Gafni, A., \& Whelan, T. (1997). Shared decision-making in the medical encounter: What does it mean?(or it takes at least two to tango). Social Science \& Medicine, 44(5), 681-692.

Chong, W. W., Aslani, P., \& Chen, T. F. (2013). Multiple perspectives on shared decisionmaking and interprofessional collaboration in mental healthcare. Journal of Interprofessional Care, 27(3), 223-230. doi:10.3109/13561820.2013.767225

Clarke, E., Puschner, B., Jordan, H., Williams, P., Konrad, J., Kawohl, W., . . . Slade, M. (2015). Empowerment and satisfaction in a multinational study of routine clinical practice. Acta Psychiatrica Scandinavica, 131(5), 369-378. doi:http://dx.doi.org/10.1111/acps.12365

Corrigan, P. W., Angell, B., Davidson, L., Marcus, S. C., Salzer, M. S., Kottsieper, P., . . . Stanhope, V. (2012). From adherence to self-determination: Evolution of a treatment 
paradigm for people with serious mental illnesses. Psychiatric Services (Washington, D.C.), 63(2), 169-173. doi:10.1176/appi.ps.201100065

Crawford, M. J., Robotham, D., Thana, L., Patterson, S., Weaver, T., Barber, R., . . Rose, D. (2011). Selecting outcome measures in mental health: The views of service users. Journal of Mental Health, 20(4), 336-346.

Curtis, L. C., Wells, S. M., Penney, D. J., Ghose, S. S., Mistler, L. A., Mahone, I. H., . . . Lesko, S. (2010). Pushing the envelope: Shared decision making in mental health. Psychiatric Rehabilitation Journal, 34(1), 14-22. doi:10.2975/34.1.2010.14.22

De las Cuevas, C., Rivero, A., Perestelo-Perez, L., Gonzalez, M., Perez, J., \& Peñate, W. (2011). Psychiatric patients' attitudes towards concordance and shared decision making. Patient Education and Counseling, 85(3), e245-e250.

De las Cuevas, C., Rivero-Santana, A., Perestelo-Perez, L., Perez-Ramos, J., \& SerranoAguilar, P. (2012). Attitudes toward concordance in psychiatry: A comparative, crosssectional study of psychiatric patients and mental health professionals. BMC Psychiatry, 12, 53-244X-12-53. doi:10.1186/1471-244X-12-53

De las Cuevas, C., \& Penate, W. (Dec 2014). To what extent psychiatric patients feel involved in decision making about their mental health care? relationships with sociodemographic, clinical, and psychological variables. Acta Neuropsychiatrica, 26(6), 372381. doi:http://dx.doi.org/10.1017/neu.2014.21

Deegan, P. E. (2007). The lived experience of using psychiatric medication in the recovery process and a shared decision-making program to support it. Psychiatric Rehabilitation Journal, 31(1), 62-69 8p.

Deegan, P. E. (2010). A web application to support recovery and shared decision making in psychiatric medication clinics. Psychiatric Rehabilitation Journal, 34(1), 23-28 6p. doi:10.2975/34.1.2010.23.28

Deegan, P. E., \& Drake, R. E. (2006). Shared decision making and medication management in the recovery process. Psychiatric Services (Washington, D.C.), 57(11), 1636-1639. doi:57/11/1636 [pii]

Deegan, P. E. (2014). Shared decision making must be adopted, not adapted. Psychiatric Services, 65(12), 1487. doi:http://dx.doi.org/10.1176/appi.ps.650906 
Drake, R. E., Deegan, P. E., \& Rapp, C. (2010). The promise of shared decision making in mental health.

Drake, R. E., Cimpean, D., \& Torrey, W. C. (2009). Shared decision making in mental health: Prospects for personalized medicine. Dialogues in Clinical Neuroscience, 11(4), 455463.

Durand, M., Carpenter, L., Dolan, H., Bravo, P., Mann, M., Bunn, F., \& Elwyn, G. (2014). Do interventions designed to support shared decision-making reduce health inequalities? A systematic review and meta-analysis. PloS One, 9(4), e94670.

Edbrooke-Childs, J., Jacob, J., Argent, R., Patalay, P., Deighton, J., \& Wolpert, M. (2016). The relationship between child- and parent-reported shared decision making and child-, parent-, and clinician-reported treatment outcome in routinely collected child mental health services data. Clinical Child Psychology and Psychiatry, 21(2), 324-338. doi:10.1177/1359104515591226

Eliacin, J., Salyers, M. P., Kukla, M., \& Matthias, M. S. (2015). Patients' understanding of shared decision making in a mental health setting. Qualitative Health Research, 25(5), 668-678. doi:http://dx.doi.org/10.1177/1049732314551060

Faulkner, A (2015). Randomised controlled trials: the straightjacket of mental health research? McPin Talking Point Papers: Edition 1. Available from: http://mcpin.org/talking-point-rcts-the-straightjacket-of-mental-health-research/

Gioia, D., Autrey, S., Drapalski, A. L., Glynn, S., Cohen, A. N., \& Dixon, L. B. (2014). Veterans' views of a shared decision-making process: A qualitative substudy of REORDER. American Journal of Psychiatric Rehabilitation, 17(4), 348-364. doi:http://dx.doi.org/10.1080/15487768.2014.903877

Goldner, E. M., Jeffries, V., Bilsker, D., Jenkins, E., Menear, M., \& Petermann, L. (2011). Knowledge translation in mental health: A scoping review. Healthcare Policy Politiques De Sante, 7(2), 83-98.

Hamann, J., Cohen, R., Leucht, S., Busch, R., \& Kissling, W. (2005). Do patients with schizophrenia wish to be involved in decisions about their medical treatment? The American Journal of Psychiatry, 162(12), 2382-2384. doi:162/12/2382 [pii] 
Hamann, J., Cohen, R., Leucht, S., Busch, R., \& Kissling, W. (2007). Shared decision making and long-term outcome in schizophrenia treatment. The Journal of Clinical Psychiatry, 68(7), 992-997.

Hamann, J., \& Heres, S. (2014). Adapting shared decision making for individuals with severe mental illness. Psychiatric Services (Washington, D.C.), 65(12), 1483-1486. doi:10.1176/appi.ps.201400307

Hamann, J., Leucht, S., \& Kissling, W. (2003). Shared decision making in psychiatry. Acta Psychiatrica Scandinavica, 107(6), 403-409. doi:130 [pii]

Hamann, J., Mendel, R., Meier, A., Asani, F., Pausch, E., Leucht, S., \& Kissling, W. (2011). "How to speak to your psychiatrist": Shared decision-making training for inpatients with schizophrenia. Psychiatric Services (Washington, D.C.), 62(10), 1218-1221. doi:10.1176/appi.ps.62.10.1218

Hamann, J., Mendel, R. T., Fink, B., Pfeiffer, H., Cohen, R., \& Kissling, W. (2008). Patients' and psychiatrists' perceptions of clinical decisions during schizophrenia treatment. The Journal of Nervous and Mental Disease, 196(4), 329-332. doi:10.1097/NMD.0b013e31816a62a0

Hegedus, A., \& Kozel, B. (Dec 2014). Does adherence therapy improve medication adherence among patients with schizophrenia? A systematic review. International Journal of Mental Health Nursing, 23(6), 490-497. doi:http://dx.doi.org/10.1111/inm.12089

Hetrick, S., Simmons, M., \& Merry, S. (2008). SSRls and depression in children and adolescents: The imperative for shared decision-making. Australasian Psychiatry : Bulletin of Royal Australian and New Zealand College of Psychiatrists, 16(5), 354-358. doi:10.1080/10398560802189888

Hyland, K. (2004). Disciplinary discourses, michigan classics ed.: Social interactions in academic writing University of Michigan Press.

Joosten, E. A. G., de Jong,C.A.J., de Weert-van Oene,G.H., Sensky, T., \& van der Staak,C.P.F. (2009). Shared decision-making reduces drug use and psychiatric severity in substance-dependent patients. Psychotherapy and Psychosomatics, 78(4), 245-253. doi:10.1159/000219524 
Joosten, E. A. G., DeFuentes-Merillas, L., de Weert,G.H., Sensky, T., van der Staak,C.P.F., \& de Jong,C.A.J. (2008). Systematic review of the effects of shared decision-making on patient satisfaction, treatment adherence and health status. Psychotherapy and Psychosomatics, 77(4), 219-226. doi:10.1159/000126073

Kabir, T., \& Wykes, T. (2010). That are valued by service users. Mental Health Outcome Measures, , 3.

Kaminskiy, E. (2015). The elephant in the room: A theoretical examination of power for shared decision making in psychiatric medication management. Intersectionalities: $A$ Global Journal of Social Work Analysis, Research, Polity, and Practice, 4(2), 19-38.

Latimer, E. A., Bond, G. R., \& Drake, R. E. (2011). Economic approaches to improving access to evidence-based and recovery-oriented services for people with severe mental illness. Canadian Journal of Psychiatry.Revue Canadienne De Psychiatrie, 56(9), $523-$ 529.

Lee King, P. A., Cederbaum, J. A., Kurzban, S., Norton, T., Palmer, S. C., \& Coyne, J. C. (2015). Role of patient treatment beliefs and provider characteristics in establishing patient-provider relationships. Family Practice, 32(2), 224-231. doi:10.1093/fampra/cmu085

Loh, A., Simon, D., Wills, C. E., Kriston, L., Niebling, W., \& Harter, M. (2007). The effects of a shared decision-making intervention in primary care of depression: A clusterrandomized controlled trial. Patient Education and Counseling, 67(3), 324-332. doi:S0738-3991(07)00140-1 [pii]

Mahone, I. H. (2008). Shared decision making and serious mental illness. Archives of Psychiatric Nursing, 22(6), 334-343. doi:10.1016/j.apnu.2007.11.002

Mahone, I. H., Maphis, C. F., \& Snow, D. E. (2016). Effective strategies for nurses empowering clients with schizophrenia: Medication use as a tool in recovery. Issues in Mental Health Nursing, , 1-8. doi:10.3109/01612840.2016.1157228

Matthias, M. S., Fukui, S., Kukla, M., Eliacin, J., Bonfils, K. A., Firmin, R. L., . . Salyers, M. P. (2014). Consumer and relationship factors associated with shared decision making in mental health consultations. Psychiatric Services (Washington, D.C.), 65(12), 14881491. doi:10.1176/appi.ps.201300563 
McMullen, L. M. (2012). Discourses of influence and autonomy in physicians' accounts of treatment decision making for depression. Qualitative Health Research, 22(2), 238-249. doi:10.1177/1049732311420738

Mistler, L. A., \& Drake, R. E. (2008). Shared decision making in antipsychotic management. Journal of Psychiatric Practice, 14(6), 333-344. doi:10.1097/01.pra.0000341889.97759.54

Morant, N., Kaminskiy, E., \& Ramon, S. (2015). Shared decision making for psychiatric medication management: Beyond the micro-social. Health Expectations : An International Journal of Public Participation in Health Care and Health Policy, doi:10.1111/hex.12392

Moher D, Liberati A, Tetzlaff J, Altman DG, The PRISMA Group (2009) Preferred Reporting Items for Systematic Reviews and Meta-Analyses: The PRISMA Statement. PLoS Med 6(7): e1000097. doi:10.1371/journal.pmed.1000097

Park, S. G., Derman, M., Dixon, L. B., Brown, C. H., Klingaman, E. A., Fang, L. J., . . . Kreyenbuhl, J. (2014). Factors associated with shared decision-making preferences among veterans with serious mental illness. Psychiatric Services (Washington, D.C.), 65(12), 1409-1413. doi:10.1176/appi.ps.201400131

Patel, S. R., \& Bakken, S. (2010). Preferences for participation in decision making among ethnically diverse patients with anxiety and depression. Community Mental Health Journal, 46(5), 466-473. doi:10.1007/s10597-010-9323-3

Patel, S. R., Bakken, S., \& Ruland, C. (2008). Recent advances in shared decision making for mental health. Current Opinion in Psychiatry, 21(6), 606-612. doi:10.1097/YCO.0b013e32830eb6b4

Perestelo-Perez, L., Gonzalez-Lorenzo, M., Perez-Ramos, J., Rivero-Santana, A., \& Serrano-Aguilar, P. (2011). Patient involvement and shared decision-making in mental health care. Current Clinical Pharmacology, 6(2), 83-90. doi:BSP/CCP/E-Pub/0043 [pii]

Quirk, A., Chaplin, R., Lelliott, P., \& Seale, C. (2012). How pressure is applied in shared decisions about antipsychotic medication: A conversation analytic study of psychiatric outpatient consultations. Sociology of Health \& Illness, 34(1), 95-113. doi:10.1111/j.1467-9566.2011.01363.x 
Quirk, A. (2015) Obstacles to Shared Decision-Making in Psychiatric Practice: Findings from three qualitative, observational studies. LAP LAMBERT: Saarbrucken.

Ramon, S., Healy, B., \& Renouf, N. (2007). Recovery from mental illness as an emergent concept and practice in australia and the UK. The International Journal of Social Psychiatry, 53(2), 108-122.

Ramos Pozon, S. (2016). Shared decision making in mental health: Myths, barriers, and benefits. [Las decisiones compartidas en salud mental: mitos, barreras y beneficios] Revista De Psiquiatria Y Salud Mental, doi:S1888-9891(16)00020-3

Raue, P. J., Schulberg, H. C., Lewis-Fernandez, R., Boutin-Foster, C., Hoffman, A. S., \& Bruce, M. L. (2010). Shared decision-making in the primary care treatment of late-life major depression: A needed new intervention? International Journal of Geriatric Psychiatry, 25(11), 1101-1111. doi:10.1002/gps.2444

Roberts, L. W., Warner, T. D., Brody, J. L., Roberts, B., Lauriello, J., \& Lyketsos, C. (2002). Patient and psychiatrist ratings of hypothetical schizophrenia research protocols: Assessment of harm potential and factors influencing participation decisions. American Journal of Psychiatry, 159(4), 573-584.

Seale, C., Chaplin, R., Lelliott, P., \& Quirk, A. (2006). Sharing decisions in consultations involving anti-psychotic medication: A qualitative study of psychiatrists' experiences. Social Science \& Medicine (1982), 62(11), 2861-2873. doi:S0277-9536(05)00584-8 [pii]

Shepherd, A., Shorthouse, O., \& Gask, L. (2014). Consultant psychiatrists' experiences of and attitudes towards shared decision making in antipsychotic prescribing, a qualitative study. BMC Psychiatry, 14, 127-244X-14-127. doi:10.1186/1471-244X-14-127

Simmons, M., Hetrick, S., \& Jorm, A. (2010). Shared decision-making: Benefits, barriers and current opportunities for application. Australasian Psychiatry : Bulletin of Royal Australian and New Zealand College of Psychiatrists, 18(5), 394-397. doi:10.3109/10398562.2010.499944

Simos, G. (2012). Collaboration in psychopharmacotherapy. Journal of Clinical Psychology, 68(2), 198-208. doi:10.1002/jclp.21836

Stacey, G., Felton, A., Morgan, A., Stickley, T., Willis, M., Diamond, B., . . Dumenya, J. (2016). A critical narrative analysis of shared decision-making in acute inpatient mental 
health care. Journal of Interprofessional Care, 30(1), 35-41. doi:10.3109/13561820.2015.1064878

Stein, B. D., Kogan, J. N., Mihalyo, M. J., Schuster, J., Deegan, P. E., Sorbero, M. J., \& Drake, R. E. (2013). Use of a computerized medication shared decision making tool in community mental health settings: Impact on psychotropic medication adherence. Community Mental Health Journal, 49(2), 185-192. doi:10.1007/s10597-012-9528-8

Velligan, D. I., Roberts, D. L., Sierra, C., Fredrick, M. M., \& Roach, M. J. (2016). What patients with severe mental illness transitioning from hospital to community have to say about care and shared decision-making. Issues in Mental Health Nursing, , 1-6. doi:10.3109/01612840.2015.1132289

Woltmann, E. M., \& Whitley, R. (2010). Shared decision making in public mental health care: Perspectives from consumers living with severe mental illness. Psychiatric Rehabilitation Journal, 34(1), 29-36. doi:10.2975/34.1.2010.29.36

\section{Appendices}

\section{Appendix 1: Search terms}

'shared decision making' OR 'SDM' AND 'mental disorder”' OR 'mental disease' OR 'mental problem' OR 'mental difficult*' OR 'mental health' OR 'mental illness*' OR 'psychiatr”' OR 'psychiatr* health', OR psychiatr* illness*' OR 'psychiatr* disorder' OR 'psychiatr* problem' OR 'psycho*' OR 'psychol* health' OR 'psychol* illness*'OR 'psychol* disorder' OR 'psychol* problem' OR 'depression' OR 'anxiety' OR 'schizophrenia' OR 'bipolar' OR 'post-traumatic stress' OR ‘PTSD' OR 'self-harm' OR 'self-injury' OR ‘suicid”' OR 'personality disorder”. 